\title{
A Comparative Study on Antiradical and Antimicrobial Properties of Red Grapes Extracts Obtained from Different Vitis vinifera Varieties
}

\author{
Nada El Darra ${ }^{1,2}$, Joanna Tannous ${ }^{1}$, Paulette Bou Mouncef ${ }^{3}$, James Palge ${ }^{3}$, Joseph Yaghi ${ }^{1}$, \\ Eugène Vorobiev $^{2}$, Nicolas Louka ${ }^{1}$, Richard G. Maroun ${ }^{1 *}$ \\ ${ }^{1}$ Biochemistry Unit and Research and Analysis Center, Faculty of Sciences, Saint-Joseph University of Beirut, Beirut, Lebanon; \\ ${ }^{2}$ Research Center of Royallieu, Unit of Transformations of Integrated Renewable Matter, Department of Chemical Engineering, \\ University of Technology of Compiegne, Compiegne Cedex, France; ${ }^{3}$ Château KSARA, S.A.L, Ksara, Békaa Valley, Lebanon. \\ Email: *richard.maroun@usj.edu.lb
}

Received August $9^{\text {th }}, 2012$; revised September $9^{\text {th }}, 2012$; accepted September $16^{\text {th }}, 2012$

\begin{abstract}
The present work is devoted to the study of antiradical and antimicrobial activities of phenolic compounds extracted from different grapevine varieties grown in the Bekaa plane-Lebanon. The amount of phenolic compounds in selected grape extracts was determined by the Folin-Ciocalteau method. Phenolic composition was specified by high performance liquid chromatography. Free radical scavenging activity was examined by using the (2,2'-diphenyl-1-picrylhydrazyl) DPPH assay. The potential antimicrobial activity was studied using a new quantitative method developed during this work. This activity was tested against several microbial pathogens, including a Gram-positive strain (Listeria monocytogenes), two Gram-negative strains (Escherichia coli and Salmonella arizonae) and a fungal strain (Candida albicans). According to the results of the present screening study, a great variability in the composition of phenolic compounds in red grape extracts was detected. All phenolic compounds extracts, demonstrated important scavenging properties and antimicrobial effect against bacterial and fungal strains. Yet, a different response degree was noticed depending on the tested microorganism and the phenolic composition of grape extracts. Antimicrobial activity was more effective against Gram-positive than Gram-negative and yeast strains. Furthermore, our results highlighted a significant role of synergistic effect between various phenolic compounds in the free radical scavenging and antimicrobial activities.
\end{abstract}

Keywords: Phenolic Compounds; DPPH; HPLC-DAD; Antimicrobial; Antiradical; Grapevines; Synergistic Effect

\section{Introduction}

Phenolic compounds make up one of the major families of secondary metabolites widely distributed in the plant kingdom, and they are found in foods of vegetable origin, constituting an integral part of our daily diet [1]. Grapes contain large amounts of phenolic compounds in skins, pulp and seeds, which are partially transferred to wine during red wine-making [2,3]. Currently, grape compounds have attracted increased attention especially in the field of nutrition, health and medicine.

Structurally, phenolic compounds comprise an aromatic ring, bearing one or more hydroxyl substituents, and range from simple phenolic molecules such as phenolic acid to highly polymerized compounds such as tannins [4]. Phenolic compounds are divided into several classes according to the number of phenol rings that they

\footnotetext{
*Corresponding author.
}

contain and to the structural elements that bind these rings to one another [5]. Phenolic grape and wine compounds can be divided into two groups: non-flavonoid (Hydroxybenzoic and Hydroxycinnamic acids, Stilbenes) and flavonoid compounds (Anthocyanins, Flavan-3-ols and Flavonols) [6].

Phenolic compounds are considered to be the most important components of red wine, due to their direct relationship with its color, astringency, bitterness, and susceptibility to oxidation reactions [7]. Furthermore, phenolic compounds are known by their potent antioxidant, antimutagenic, antibacterial, antiviral, antifungal and antiulcer activities [8].

Indeed, due to the mobility of the phenolic hydrogen, phenolic compounds are able to scavenge free radicals generated continuously by endogenous factors such as normal physiological metabolism and also by exogenous factors including smoking, pollution, infections, sun ex- 
posure and others [9]. The loss of hydrogen causes the formation of a highly stabilized mesomeric radical.

Several studies have highlighted that phenolic compounds by virtue of their antioxidant capacity participate in the prevention of various chronic diseases in which an oxidative stress is potentially involved [10].

Nowadays bacteria, yeasts and free radicals cause real health problems because of their involvement in many diseases mainly those in which an oxidative stress is involved such as cancer and cardiovascular disease and in food borne diseases [11]. Currently there is a growing scientific interest to use natural antibacterial compounds, as biopreservatives face to conventional synthetic additives, due to consumer preferences towards more natural and healthier products [12]. Thus the role of natural phenolic compounds extracted from plant reaches its paroxyme and the addition of these natural compounds to food products has therefore become popular as a means of increasing shelf life and to reduce wastage and nutriational losses by inhibiting microbial growth and delaying oxidation [13].

The aim of the present work was to assess the antiradical and antimicrobial activities of phenolic compounds extracted from grapevine varieties of Château KSARA-Bekaa-Lebanon. Several previous studies have been conducted to evaluate antioxidant activity as well as antimicrobial activity of phenolic extract from wines or grapes seeds, skins and pulps [14-16]. As a first study in Lebanon two of the most important biological activities of phenolic compounds, antiradical and antimicrobial, have been tested on phenolic extracts prepared from the whole grape berries. The phenolic content of these grape extracts was determined by the Folin-Ciocalteau method. An HPLC-DAD method was conducted for the determination and quantification of the main phenolic compounds belonging to flavonoids and non-flavonoids molecules in order to determine the influence of these molecules towards their bioactive properties. The evaluation of antiradical activity was based on the capacity of a sample to scavenge the DPPH radical. In this work, we describe a new and innovative quantitative method for the evaluation of the antimicrobial activity of red grapes phenolic compounds against various pathogenic strains, such as Gram-positive and Gram-negative bacteria and yeasts.

\section{Materials and Methods}

\subsection{Plant Material}

The grapes examined in our study were harvested in the vintage 2009 , at optimum maturity from vineyards in the province of Bekaa-Château KSARA S.A.L, Lebanon. At their optimum phenolic maturity, these grapes have both, a high content of phenolic compounds and a good extractability [17].

All samples analyzed were $V$. vinifera species from different cultivars. The varieties chosen were: Merlot, Syrah, Cabernet franc and Cabernet Sauvignon, the most important red grape varieties that can be encountered in the Lebanese vineyard. We should notice that this study is applied for the first time in the Lebanese vineyard.

\subsection{Chemicals and Reagents}

Solvents used for high-performance liquid chromatographic analysis were: Methanol (Merck, Darmstadt, Germany) and Formic acid (Scharlau, Barcelona, Spain) of HPLC ultra gradient grade. HPLC grade water (Merck, Darmstadt, Germany) was also used. Folin-Ciocalteu's phenol reagent; Sodium Carbonate; 2,6-di-tert-butyl-4methylphenol (BHT); 2,2-diphenyl-bpicrylhydrazyl(DPPH) radical and Tris- $\mathrm{HCl}$ buffer were obtained from Sigma (Aldrich).

Phenolic Standards: Gallic acid, Protocatechin, Hydroxybenzoic acid, Catechin, Epigallocatechin, Caffeic acid, Chlorogenic acid, Epicatechin, $p$-Coumaric acid, Gallocatechin gallate, Ferulic acid, Resveratrol, Cinnamic acid, Rutin, Myricetin, Quercetin and Kaempferol were purchased from Sigma (Aldrich) Laboratories.

\subsection{Microbial Strains and Growth Conditions}

Antimicrobial activity was screened against two Gram negative bacteria: Escherichia coli ATCC 10536 (E. coli) and Salmonella arizonae ATCC 13314 (S. arizonae), one Gram positive bacteria: Listeria monocytogenes ATCC 19111 (L. monocytogenes), and one yeast strain: Candida albicans ATCC 10231 (C. albicans).

Chloramphenicol (Sigma, Aldrich) and Amphotericin B (Sigma, Aldrich) were used respectively as the reference antimicrobial and antifungal standards.

All strains were cryo-preserved at $-80^{\circ} \mathrm{C}$. E. coli was cultured in Luria Broth, S. arizonae in Trypticase Soy Broth (BioMérieux, Marcy L'Etoile, France), L. monocytogenes in Trypticase Soy Broth-Yeast Extract (BioMérieux, Marcy L'Etoile, France), while the yeast strain C. albicans was maintained in Yeast Glucose Chloramphenicol Broth.

For experimental use, the microorganisms were sub cultured in agar media, incubated for $24 \mathrm{~h}$ at $37^{\circ} \mathrm{C}$ for bacteria and $30^{\circ} \mathrm{C}$ for yeast and used as the source of inoculums for each experiment. After incubation, each microorganism was suspended in $5 \mathrm{~mL}$ of appropriate broth and incubated for one hour at adequate temperature with agitation. Cultures growth was followed by the turbidity measurement at $630 \mathrm{~nm}$, until it achieved the turbidity of 0.5 McFarland standard, which is equal to an 
inoculum containing approximately $10^{8} \mathrm{cfu} / \mathrm{mL}$ [18].

\subsection{Sample Preparation and Extraction}

In our study, 239 samples of red grapes extracts from different varieties were analyzed and quantified. According to their phenolic maturity, four samples presenting the greatest phenolic maturity were selected. The phenolic constituents from the whole grape berries were extracted using conventional solvent extraction procedure. The extraction protocol was developed and optimized in our laboratory [19]. Briefly, to extract phenolic compounds, ten grams of homogenized grape berries (in high speed grinder) were mixed with $15 \mathrm{~mL}$ of acetone solvent (acetone/water 85/15, v/v) at room temperature. Contact time was 3 to 4 days. When the extraction is completed, the mixture is centrifuged at $2500 \mathrm{rpm}$ for 15 minutes, at $20^{\circ} \mathrm{C}$. When completed, the supernatant was recovered and transferred into new tubes and incubated for two days at $40^{\circ} \mathrm{C}$ to ensure the complete evaporation of the solvent. After the extraction, samples were filtered through $0.2 \mu \mathrm{m}$ syringe filters. The resulting extract was stored at $-20^{\circ} \mathrm{C}$ protected from light.

\subsection{Determination of Total Phenolic Compounds Content Using Folin-Ciocalteau Method}

The total phenolic content was determined according to Folin Ciocalteu (FC) method [20]. An aliquot of $10 \mu \mathrm{l}$ of the sample solution was mixed with $100 \mu$ l of commercial Folin-Ciocalteau reagent and $1580 \mu \mathrm{l}$ of water. After a brief incubation at room temperature $(5 \mathrm{~min}), 300 \mu \mathrm{l}$ of saturated sodium carbonate was added. The color generated was read after $2 \mathrm{~h}$ at room temperature at $760 \mathrm{~nm}$ using a UV-Vis spectrophotometer (UV-9200, BioTECH Engineering Management, UK). A calibration plot of absorbance versus phenol concentration was made using Gallic acid as standard. The total phenolic compounds content in samples was evaluated from the generated absorbance value.

\subsection{Determination of Anthocyanin Concentration}

The concentration of free anthocyanins in red grapes extracts selected was analyzed by bleaching with bisulphite [21]. The bisulfite bleaching procedure requires the preparation of two samples, each containing $1 \mathrm{ml}$ of grape extract, $1 \mathrm{ml}$ of ethanol (EtOH), $0.1 \%$ Chlorydric acid $(\mathrm{HCl})$ and $20 \mathrm{ml}$ of $\mathrm{HCl}$ at $2 \%(\mathrm{pH} 0.8)$. For the two samples, $4 \mathrm{ml}$ of water $\left(\mathrm{H}_{2} \mathrm{O}\right)$ are added to $10 \mathrm{ml}$ of the first sample, $4 \mathrm{ml}$ of sodium bisulfite solution, are added to $10 \mathrm{ml}$ of the second sample and the mixture is diluted by half. The difference in optical density $(\Delta \mathrm{OD})$ at 520 $\mathrm{nm}$ is measured on a $1 \mathrm{~cm}$ optical path. By comparison with a standardized anthocyanin solution, the concentration is given by the following equation:

$$
\mathrm{C}(\mathrm{mg} / \mathrm{l})=\Delta \mathrm{OD} \times 875
$$

875 is the slope of the calibration curve obtained from Malvidin-3-glucoside.

\subsection{HPLC Analysis}

Polyphenol analyses of the extracts prepared from the whole red grapes were performed by high-performance liquid chromatography (HPLC). Prior to analytical chromatography, samples and standards were purified by filtration through $0.2 \mu \mathrm{m}$ syringe filters to remove interferences of sugars and organic acids from the crude sample. An equipment consisting of a liquid chromatographyKNAUER apparatus coupled to a diode array detector was employed. Analyses were performed on a Spherisorb ODS- $2(5 \mathrm{~mm}, 250 \times 4.6 \mathrm{~mm})$, at a flow rate of 1 $\mathrm{mL} \cdot \mathrm{min}^{-1}$, using a $20 \mu \mathrm{L}$ injection volume, detection at $280 \mathrm{~nm}$ and $320 \mathrm{~nm}$, and the elution programme given in Table 1. Eluent A was $2 \%$ aqueous Formic acid and eluent B: $69 \%$ Methanol $(\mathrm{MeOH}), 29 \%$ HPLC water and $2 \%$ Formic acid. Identification was based on comparing retention times of the peaks detected with those of originnal compounds, and on UV-Vis on-line spectral data. Quantification was accomplished using the phenolic standards solutions. Results were expressed as $\mathrm{mg} / \mathrm{ml}$ grape extract volume [22].

\subsection{Biological Activity of Grape Extracts}

The antiradical and antimicrobial capacity of phenolic compounds, in a general was well known $[23,24]$. As previously described, individual phenolic compounds present in grape extracts were identified and quantified, but we choose to submit the entire extracts to the biological activity studies. In fact, total food extracts may be

Table 1. Linear gradient used for the separation of phenolic compounds present in grapes.

\begin{tabular}{ccc}
\hline Time (min) & Solvent A (\%) & Solvent B (\%) \\
\hline 0 & 100 & 0 \\
3 & 100 & 0 \\
10 & 90 & 10 \\
60 & 60 & 40 \\
80 & 40 & 60 \\
105 & 20 & 80 \\
120 & 0 & 100 \\
140 & 100 & 0 \\
\hline
\end{tabular}


more beneficial than isolated constituents, since a bioactive individual component can change its properties in the presence of other compounds present in the extract [25] corresponding to a synergistic effect.

\subsubsection{Free Radical Scavenging Activity}

The scavenging activity of DPPH free radical by grape must was determined according to the method reported by $[26,27]$. The free radical scavenging activity of extracts were examined by comparing to those of known antioxidants such as butylhydroxytoluene (BHT) (a synthetic antioxidant) and resveratrol (a natural antioxidant) by 1,1-diphenyl-2-picrylhydrazyl (DPPH). Each extract or positive control (BHT or Resveratrol) was diluted at a series of extract concentrations of $1,5,10$ and $50 \mu \mathrm{g} / \mathrm{mL}$. In each reaction, an aliquot of $50 \mu \mathrm{L}$ of the diluted extract was added to $3.9 \mathrm{~mL}$ of DPPH solution in Methanol $(0.1 \mathrm{mM})$ and $450 \mu \mathrm{L}$ of Tris- $\mathrm{HCl}$ buffer. Absorbance at $517 \mathrm{~nm}$ was measured after $30 \mathrm{~min}$ of incubation at room temperature using pure Methanol as a blank. All samples were analyzed in duplicate.

The percentage of inhibition of the DPPH was determined as follows:

$$
\begin{gathered}
\% \text { inhibition }=[(\text { absorbance of control }- \text { absorbance of } \\
\text { test sample }) / \text { absorbance of control }] \times 100
\end{gathered}
$$

The free radical scavenging activity of Lebanese grape extracts was evaluated by the decrease in the peak area of the DPPH radical which exhibits a deep purple color with maximum absorption at $517 \mathrm{~nm}$. Antioxidant molecules can quench DPPH free radicals, resulting in decoloration of DPPH because of their conversion into a colorless product.

\subsubsection{Antimicrobial Activity}

To determine the antimicrobial effect of the grape extracts, a new quantitative method was adapted. Aliquots of $200 \mu \mathrm{L}$ bacterial or fungal pure cultures previously prepared (L. monocytogenes or S. arizonae or E. coli or C. albicans) were mixed with $200 \mu \mathrm{L}$ of each sample or antimicrobial agent (Chloramphenicol), antifungal agent (Amphotericin B) and phenolic standards (Resveratrol, BHT, Gallic acid) used as positive controls at a concentration of $5 \mathrm{mg} / \mathrm{mL}$ and grown at $37^{\circ} \mathrm{C}$ (for bacterial strains) and $30^{\circ} \mathrm{C}$ (for fungal strain) for 24 hours with agitation. A negative control was also applied under the same experimental conditions, by replacing the grape extracts with the adequate broth for each microbial strain.

After appropriate incubation, serial dilutions from stock solutions were prepared in adapted broth for each strain. $500 \mu \mathrm{l}$ from the $10^{-7}$ dilution was suspended into $20 \mathrm{~mL}$ agar medium and homogenized, then transferred into Petri dishes.
All plates were incubated for $24 \mathrm{~h}$ at $37^{\circ} \mathrm{C}$ for bacterial strains and $30^{\circ} \mathrm{C}$ for the fungal strain. After incubation the numbers of bacteria or yeast colonies that grow on each plate were counted.

The inhibitory effect was calculated using the following formula:

$$
\% \text { Inhibition }=(1-\mathrm{T} / \mathrm{C}) \times 100,
$$

where $\mathrm{T}=\mathrm{cfu} / \mathrm{ml}$ of test sample and $\mathrm{C}=\mathrm{cfu} / \mathrm{ml}$ of negative control [28].

\subsection{Statistical Analysis}

Each modality was conducted in duplicates and analysis repeated twice. Means and standard deviations of data were calculated. Two way analysis of variance (ANOVA) followed by Fisher's LSD (Least Significant Difference) were performed to compare the means of the different investigated responses and to determine statistical significance. For each analysis, significance level of 5\% was assumed. All statistical analyses were performed using Statgraphics 5.1 (Statpoint Technologies Inc., USA).

\section{Results and Discussion}

\subsection{The Content of Polyphenols and Anthocyanins in Grape Extracts}

The phenolic composition is an important quality parameter of red grape, which affects the quality of the resulting wines. Its knowledge is essential to classify red grapes varieties. In our study, 239 samples of red grapes extracts from different varieties were analyzed and quantified. Among these extracts, four were chosen for their high phenolic content and antiradical activities.

In order to classify the Lebanese grape varieties, a prior analysis of the phenolic and anthocyanin content of these four grapes extracts was done. Table 2 presents the total concentration of phenolic compounds (mg GAE/L) and anthocyanins concentrations $(\mathrm{mg} / \mathrm{L})$ of the Lebanese red grapes extracts (Merlot, Syrah, Cabernet Sauvignon and Cabernet Franc) used in this study. Based on statistical analysis by Fisher's LSD test. Table 2 showed significant differences between phenolic content of the different grapes cultivars. Results showed that the total phenolic content of the different varieties was quite variable. This result was also proved [29], within a study on the polyphenolic content of different grape varieties. The variability found in total phenolic content between different cultivars confirmed the hypothesis that genetic and environmental factors [30-32], are key influencers of a cultivar's phenolic content.

Table 2 showed that the anthocyanin concentration is also dependant from the variety. However, statistical analysis showed that only Syrah presents significant dif- 
ferences comparing to the other varieties. Whereas, nonsignificant differences were noticed between anthocyanin concentration contents of the other cultivars (Merlot, Cabernet Sauvignon and Cabernet Franc). This result confirmed the hypothesis that apart from the genetic background, several agroecological factors, such as maturation [33], ripening stage [34], cultivar [31], climate [35], stress levels [32], soil conditions vine water status and cultural practices) are able to impact the level of polyphenols and anthocyanin contents of red grape extracts. Therefore, these factors can be used to modify the phenolic composition of red grapes, which explains the differences between the phenolic and anthocyanin con- centration for different red grape varieties.

Every family of polyphenols is directly responsible for the special characteristics of specific grapes varieties. In order to explain the physiological activities of phenolic compounds present in our different red grape extracts, an identification and quantification of these compounds were done before testing their antiradical and antimicro0 bial activities. Therefore, different phenolic compounds flavonoids and non-flavonoids were chosen as standards because of their biological and pharmacological interest and their contents were determined by reverse-phase HPLC (Tables 3 and 4). The concentration of the components was calculated from each chromatogram peak area.

Table 2. The weight (g) of grape berries, the phenolic (mg GAE/L) and the anthocyanin $(\mathrm{mg} / \mathrm{L})$ contents in the red grape varieties. The given values are the means of two repetitions.

\begin{tabular}{ccccc}
\hline Grape varieties & Codex & $\begin{array}{c}\text { Weight (g) of } 100 \text { grape } \\
\text { berries }\end{array}$ & $\begin{array}{c}\text { Polyphenols concentration } \\
(\mathrm{mg} / \mathrm{L})\end{array}$ & $\begin{array}{c}\text { Anthocyanins concentration } \\
(\mathrm{mg} / \mathrm{L})\end{array}$ \\
\hline Merlot & KAM33 & $151.3^{\mathrm{b}}$ & $8101.4^{\mathrm{d}}$ & $530^{\mathrm{b}}$ \\
Syrah & ITS9 & $176.3^{\mathrm{a}}$ & $13801.4^{\mathrm{a}}$ & $58^{\mathrm{a}}$ \\
Cabernet Sauvignon & TACS22 & $136.5^{\mathrm{c}}$ & $12858.5^{\mathrm{b}}$ & $528^{\mathrm{b}}$ \\
Cabernet Franc & ITCF4 & $123.5^{\mathrm{d}}$ & $8815.7^{\mathrm{c}}$ & $528^{\mathrm{b}}$ \\
\hline
\end{tabular}

a,b,c,d Marks with the same superscript letters were not significantly different within the same column (LSD test, $5 \%$ level).

Table 3. Non-flavonoid contents of the red grape varieties. (-) corresponds to a none-determined quantity.

\begin{tabular}{|c|c|c|c|c|c|c|c|c|c|c|}
\hline \multirow{3}{*}{$\begin{array}{c}\text { Grape } \\
\text { varieties }\end{array}$} & \multirow{3}{*}{ Codex } & \multicolumn{9}{|c|}{ Non-flavonoids (mg/ml) } \\
\hline & & \multirow{2}{*}{$\begin{array}{c}\begin{array}{c}\text { Stilbenes } \\
(\mathrm{mg} / \mathrm{L})\end{array} \\
\text { Resveratrol }\end{array}$} & \multicolumn{8}{|c|}{ Phenolic acids (mg/ml) } \\
\hline & & & $\begin{array}{l}\text { Chlorogenic } \\
\text { acid }\end{array}$ & $\begin{array}{l}\text { Caffeic } \\
\text { acid }\end{array}$ & $\begin{array}{c}\text { Gallic } \\
\text { acid }\end{array}$ & $\begin{array}{l}\text { Ferrulic } \\
\text { acid }\end{array}$ & $\begin{array}{l}\text { Hydroxybenzoic } \\
\text { acid }\end{array}$ & $\begin{array}{l}\text { Cinnamic } \\
\text { acid }\end{array}$ & $\begin{array}{c}p \text {-Coumaric } \\
\text { acid }\end{array}$ & $\begin{array}{c}\text { Protocatechuic } \\
\text { acid }\end{array}$ \\
\hline Merlot & KAM33 & 0.20 & 0.04 & 0.08 & 0.37 & - & 0.02 & - & 0.11 & 0.05 \\
\hline Syrah & ITS9 & 0.84 & 1.04 & - & 0.14 & 0.05 & 0.01 & 0.98 & 0.06 & 0.33 \\
\hline $\begin{array}{l}\text { Cabernet } \\
\text { Sauvignon }\end{array}$ & TACS 22 & 1.67 & 0.03 & 0.01 & 0.98 & - & 1.47 & - & 0.01 & 0.18 \\
\hline $\begin{array}{l}\text { Cabernet } \\
\text { Franc }\end{array}$ & ITCF4 & 0.97 & 0.02 & 0.01 & 0.13 & - & - & 1.49 & 0.00 & 0.12 \\
\hline
\end{tabular}

Table 4. Flavonoid contents of the red grape varieties. (-) corresponds to a none determined quantity.

\begin{tabular}{cccccccccc}
\hline \multirow{2}{*}{$\begin{array}{c}\text { Grape } \\
\text { varieties }\end{array}$} & Codex & \multicolumn{7}{c}{ Flavonoids (mg/ml) } \\
\cline { 3 - 9 } & & Quercetin & Kampherol & Myricetin & Rutin & Catechin & Epicatechin & Epigallocatechin & GallocatechinGallate \\
\hline Merlot & KAM33 & 0.05 & 0.04 & 0.42 & - & 0.17 & 0.23 & - & 0.99 \\
Syrah & ITS9 & 0.28 & 0.10 & 0.21 & - & - & - & - & 1.10 \\
$\begin{array}{c}\text { Cabernet } \\
\text { Sauvignon }\end{array}$ & TACS22 & 0.10 & - & 0.30 & 1.81 & 0.22 & - & - & - \\
Cabernet Franc & ITCF4 & - & - & 0.09 & - & - & 0.4 & 0.15 & 0.65 \\
\hline
\end{tabular}


HPLC analysis of phenolic compounds in red grape extracts showed that most of the non-flavonoid and flavonoid compounds chosen have been identified in the different red grapes varieties of vintage 2009. Table 3 showed that the amount of non-flavonoid content and especially resveratrol is dependent on the red grapes varieties and that the Cabernet Sauvignon variety was richer in resveratrol than other cultivars, which was confirmed by Sun et al., 2006 [36]. The latter confirmed that stilbenes (Resveratrol) content is largely dependent of grape varieties. The phenolic pattern of grape extracts contains Cholorogenic acid, Caffeic acid, Gallic acid, Ferulic acid, Hydroxybenzoic acid, Cinnamic acid, $p$ Coumaric acid and Protocatechuic acid. The concentration of each of these compounds varies between different cultivars.

Moreover Table 4 showed that the flavonoid content of grape extracts was variety dependent as well. The phenolic pattern of grape extracts contains Quercetin, Kaempferol, Myricetin, Rutin, Catechin, Epicatechin, Epigallocatechin, and Gallocatechin gallate.

Also Table 4 showed that Merlot and Cabernet Sauvignon varieties were the only cultivars that contain Catechin. This result was confirmed by other authors who showed that Cabernet Sauvignon and Merlot were the cultivar in which the Catechin is the main compound [37, 38].

To determine the total phenolic content of the grapes varieties, the total of flavonoid, non-flavonoid and phenolic acid contents of the four red grapes varieties were calculated (Table 5). Table 5 showed that flavonoid, non-flavonoid and phenolic acid contents were significantly different between the four grape varieties. Of these compounds, non-flavonoid-compounds especially phenolic acids are in higher concentration than the flavonoid compound at the exception of the variety Merlot KAM 33.

Table 5 showed that the greatest range of non-flavonoid was found in the grape extract of Cabernet Sauvignon TACS22 and the lowest in the grape extract of Merlot KAM33, with high flavonoid content for both cultivars. Therefore to present a global overview on the phenolic profiles of TACS22 and KAM33, two representative chromatograms of these two samples are illustrated in Figure 1.

Figure 1(a) represents the chromatogram for the Merlot KAM33 and Figure 1(b) for the Cabernet Sauvignon TACS22. The results showed that non-flavonoid compound especially Resveratrol were present in greater amounts in Cabernet Sauvignon TACS2 than in Merlot KAM33.

\subsection{Radical Scavenging Effect Assay}

The free radical scavenging activity of red grape extracts was assessed by DPPH assay. From a methodological point of view, the DPPH (2,2,-diphenyl-1-picryhydrazyl) method [39], is recommended as easy and accurate methods for measuring the antiradical activity of fruit and vegetable juice or extracts.

The scavenging effects of ethanolic extracts from red grapes from different varieties were examined and compared. Several concentrations of red grapes extracts ranging from $1-50 \mu \mathrm{g} / \mathrm{mL}$ were tested for their scavenging activity in vitro model. As shown in Figure 2, the amount of DPPH decreased in the presence of grape extracts. Therefore, radical scavenging activity increased with increasing percentage of the free radical inhibition. Figure 2 showed also that free radicals were scavenged by the test compound in a concentration dependent manner in the model. Figure 2 showed that all the test samples have a significant inhibitory activity against the DPPH radical, but the higher inhibition of DPPH radical by extracts samples was observed at a range of $50 \mu \mathrm{g} / \mathrm{mL}$. This result is in agreement with the study of the scavenging activity of the seed methanolic extracts of three Vitis vinifera realized by Saïdani Tounsi M. et al. 2009 [40], who showed that all seed extracts showed remarkable DPPH radical scavenging activity at a concentration of $50 \mu \mathrm{g} / \mathrm{mL}$.

Figure 2 showed also that the scavenging activity was different between the grape varieties, which was due to the difference in their phenolic compounds contents.

To find the contribution of different phenolic content

Table 5. Flavonoid, non-flavonoid and phenolic acid contents of the red grape varieties.

\begin{tabular}{|c|c|c|c|c|}
\hline Grape varieties & Codex & Flavonoid (mg/ml) & Non-flavonoid $(\mathrm{mg} / \mathrm{ml})$ & Phenolic acid ( $\mathrm{mg} / \mathrm{ml})$ \\
\hline Merlot & KAM33 & $1.9^{\mathrm{b}}$ & $0.87^{\mathrm{d}}$ & $0.66^{\mathrm{d}}$ \\
\hline Syrah & ITS9 & $1.7^{\mathrm{c}}$ & $3.45^{\mathrm{b}}$ & $2.61^{\mathrm{b}}$ \\
\hline Cabernet Sauvignon & TACS 22 & $2.5^{\mathrm{a}}$ & $4.35^{\mathrm{a}}$ & $2.68^{\mathrm{a}}$ \\
\hline Cabernet Franc & ITCF4 & $1.3^{\mathrm{d}}$ & $2.75^{\mathrm{c}}$ & $1.79^{\mathrm{c}}$ \\
\hline
\end{tabular}

a,b,c,d Marks with the same superscript letters were not significantly different within the same column (LSD test, $5 \%$ level). 


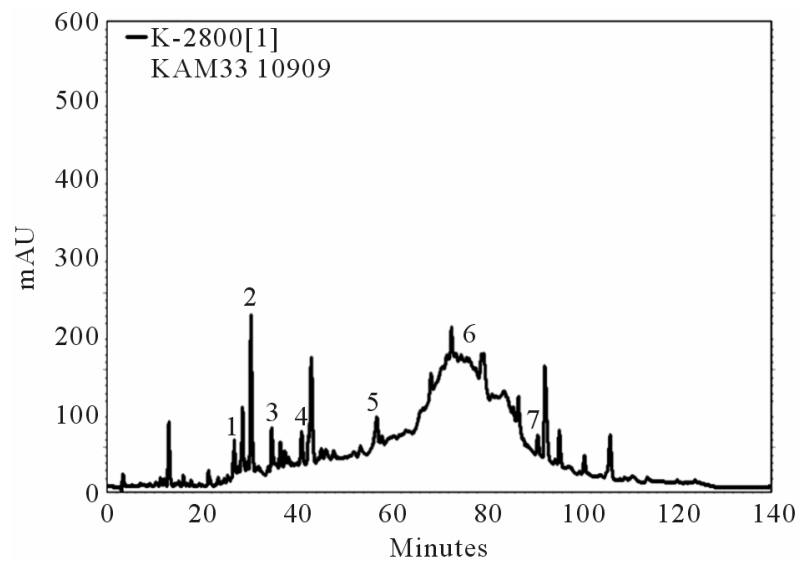

(a)

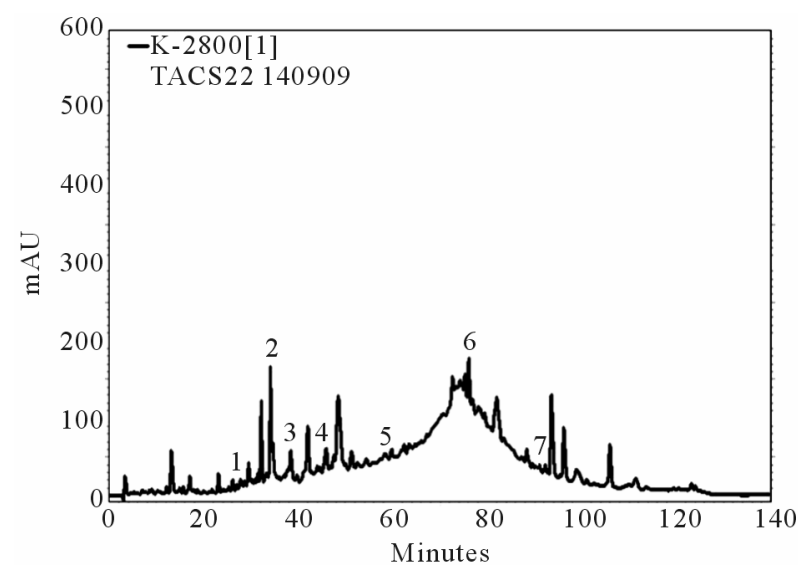

(b)

Figure 1. HPLC chromatogram of red grape extracts of two varieties (a) Merlot KAM 33 and (b) Cabernet Sauvignon TACS22. Peak identification: 1. Hydroxybenzoic acid, 2. Catechin, 3. Caffeic acid, 4. Chlorogenic acid, 5. P-coumaric acid, 6. Resveratrol, 7. Myricetin.

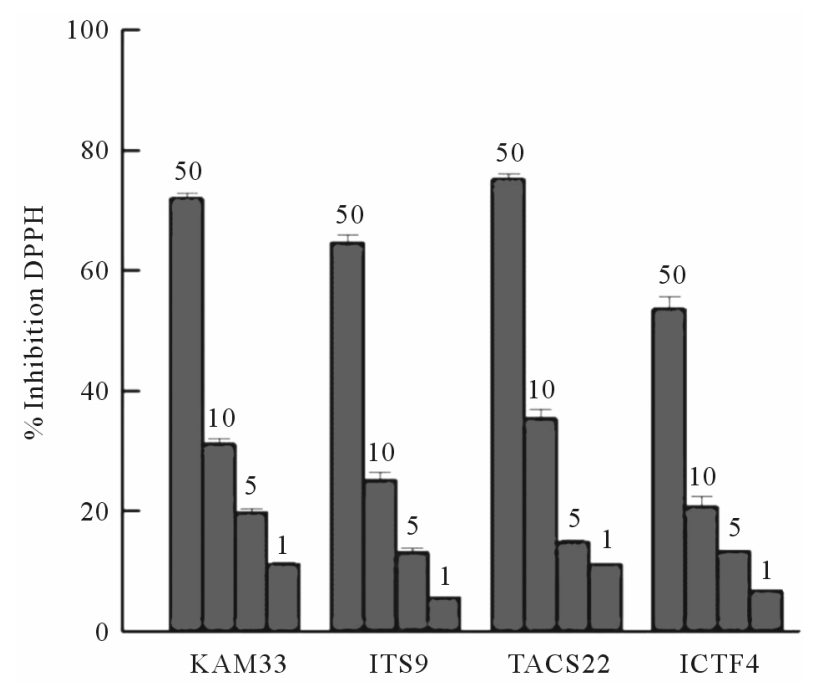

Figure 2. Free radical scavenging activity of red grapes varieties extracts measured by the DPPH assay. in the scavenging activity of the grape phenolic extracts, Table 6 presents the flavonoid and non-flavonoid contents of grape extracts with the inhibition of the free radical DPPH. A correlation between the flavonoid content and the inhibition of the DPPH radical was noticed in Table 6. In fact, it seems to be clear that the basic structure of compounds and other structural factors are very important in the scavenging mechanism [41]. Table 6 showed that the scavenging effects of red grapes on DPPH radicals increased when the flavonoid concentration increase. This result showed that flavonoid are the main responsible of the scavenging activity of red grape extracts, which was also proved by many studies $[42,43]$. Earlier studies indicated that the ability of flavonoids to incactivate peroxyl radicals was in the main better than the small phenolic antioxidants [44]. Other approaches also have established that the position and degree of hydroxylation is fundamental to the antioxidant activity of flavonoids [45].

Moreover, Table 6 showed significant differences between scavenging activities of the different grapes cultivars. Cabernet sauvignon grapes extract and merlot have the greatest activity toward DPPH radical, but there were not the extracts with the highest phenolic content. Many authors confirmed that there is an insignificant correlation between free radical scavenging capacity and phenolic content, suggesting the presence of further phenolic components or interactions involved in the antioxidant potential [46].

In fact, in the phenolic pool of red grapes, there are some secondary compounds that are important for their antioxidant activity: Catechin and Epicatechin (flavan3-ols), Quercetin [47,48] and its glycoside Rutin (flavonols), and trans-Resveratrol (stilbene). These compounds have been proven to be potent antioxidants and to have important biological, pharmacological and medicinal properties [49]. In our study, TACS22 and KAM33 represent the greatest scavenging activity due to their high concentration of these compounds. Theses extracts contain most of the flavonoids components identified by HPLC (Tables 3 and 4). A synergistic effect of these various phenolic compounds could explain the high scavenging activity of the TACS22 and KAM33 extracts. This effect was also discussed by Sun and Ho, 2005 [36] who proved that the synergistic effect of the antioxidants in the extracts should also be considered.

The Cabernet franc extract represents the lowest scavenging capacity, due to the absence of Quercetin and Catechin in this extract.

After studying the scavenging activity results, an antimicrobial studies on the efficacy of the phenolic compounds of Lebanese red grapes extracts to inactivate the bacterial and fungal strains should be discussed. 
Extracts Obtained from Different Vitis vinifera Varieties

Table 6. Flavonoid, non-flavonoid and \% of inhibition of the extracts.

\begin{tabular}{ccccc}
\hline Grape varieties & Codex & Flavonoid $(\mathrm{mg} / \mathrm{ml})$ & Non-flavonoid $(\mathrm{mg} / \mathrm{ml})$ & $\%$ inhibition DDPH \\
\hline Merlot & KAM33 & $1.9^{\mathrm{b}}$ & $0.87^{\mathrm{d}}$ & $71^{\mathrm{b}}$ \\
Syrah & ITS9 & $1.7^{\mathrm{c}}$ & $3.45^{\mathrm{b}}$ & $65^{\mathrm{c}}$ \\
Cabernet Sauvignon & TACS22 & $2.5^{\mathrm{a}}$ & $4.35^{\mathrm{a}}$ & $75^{\mathrm{a}}$ \\
Cabernet Franc & ITCF4 & $1.3^{\mathrm{d}}$ & $2.75^{\mathrm{c}}$ & $52^{\mathrm{d}}$ \\
\hline
\end{tabular}

a,b,c,d Marks with the same superscript letters were not significantly different within the same column (LSD test, $5 \%$ level).

\subsection{Antimicrobial Assays}

Due to the development of resistant microbial strains, the number of publications on antimicrobial activity of phenolic compound is increasing. The two most commonly used methods for the screening of the potential antimicrobial plant compounds were the disc diffusion test and the dilution plate assay. These techniques do not distinguish bactericidal and bacteriostatic effects and permit to determine just an approximate minimum inhibitory concentration (MIC) [50]. Recently, the microplate method was used to the screening of antimicrobial compounds. It provided a potentially useful technique for determining MICs of large numbers of test samples. It consisted on adding phenolic extract on the well of an ELISA tray filled with the exponentially growing culture (about $10^{8}$ colony-forming units $/ \mathrm{ml}$ ). The plate was incubated at $37^{\circ} \mathrm{C}$ for $18 \mathrm{~h}$, agitated and the absorbance read after the incubation were subtracted of those read before, at the same wavelength $(620 \mathrm{~nm})$. The application of this method was not adequate on the grape extract. This is due to the fact that the red grape extract and the inoculum of bacteria read at the same absorbance which induces an interference of the color of the tested substance with the bacteria. In order to avoid this problem, a new quantitative method was adapted in our study to determine the antimicrobial efficacy of the Lebanese red grape extracts. It consists on counting the numbers of bacteria or yeast colonies that grow on each plate after the addition of the phenolic extract on the plate containing the bacterial or fungal culture.

Antimicrobial activities of antimicrobials agents (Chloramphenicol), phenolic standards (Resveratrol, BHT, Gallic acid) used as positive controls (at a concentration of 5 $\mathrm{mg} / \mathrm{mL}$ ) and red grape extracts against Gram-negative strains (S. arizonae and E. coli), Gram-positive strain ( $L$. monocytogenes) and a fungal strain (C. albicans) were studied. The antimicrobial activity toward S. arizonae and E. coli (Gram-negative strains) is presented is Figure 3.

Figure 3 showed that Chloramphenicol presented the highest growth inhibition on Gram-negative strains, and that natural phenolic compounds has more effect than

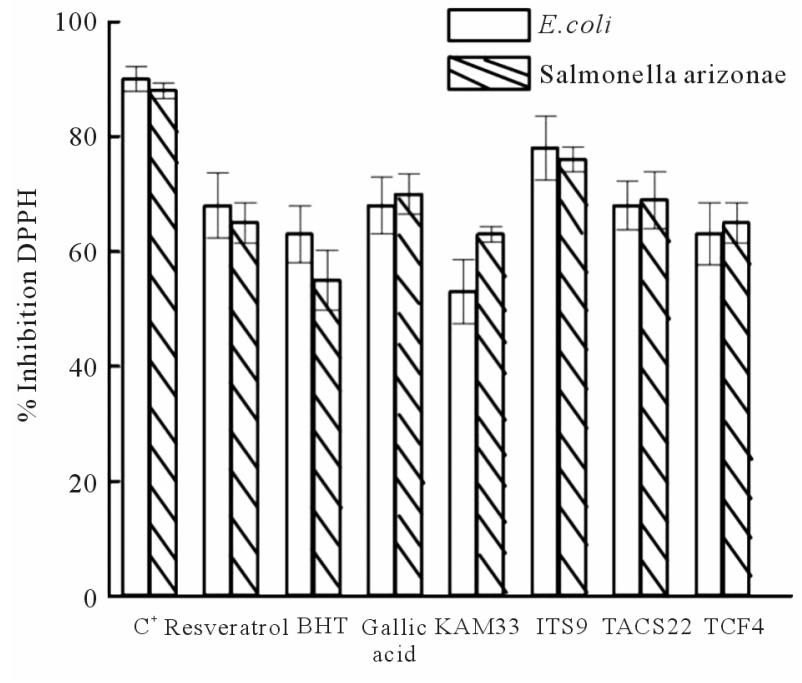

Figure 3. Antimicrobial activity of $\mathrm{C}^{+}$, phenolic standards and red grape extracts of vintage 2009 against Gram-negative strains (Salmonella arizonae and Escherichia coli).

synthetic phenolic compounds (BHT). It showed also that grapes extracts inhibited the growth of Gram-negative strains. But a different response degree was noticed between the two strains, depending on the tested microorganism to grape extracts. To explain the antimicrobial activity of phenolic extracts against Gram-negative, a relation between the phenolic content and the inhibition growth should be done. ITS9 and TACS22 exhibited more antimicrobial activity on Gram-negative strains than other grape extracts studied. This could be explained by the phenolic composition of theses 2 extracts. ITS 9 and TACS22 were rich in phenolic acids, known by its growth inhibition on Gram-negative strains. In fact, several studies showed the antimicrobial effect of phenolic acid on Gram-negative strain. Papadopoulou et al., 2005; Butkhup L. et al., $2010[14,50]$ studying the action of phenolic compounds on Gram-negative bacteria found that phenolic acids are likely to exhibit antimicrobial activity toward Gram-negative strains. Moreover ITS9 and TACS22 are also rich in Resveratrol and Quercetin, known by their antibacterial effect against $E$. coli and Salmonella [51]. Therefore, a synergetic antimicrobial 
effect noticed between phenolic acids, Resveratrol and Quercetin for ITS9 and TACS22, could explain their high antimicrobial activities toward Gram-negative strains. Figure 3 showed also that red grape extracts presented for some samples higher inhibition that phenolic standards (at $5 \mathrm{mg} / \mathrm{ml}$ ), and we should noticed that the content of these phenolic standards in grape extracts are (much lower than $5 \mathrm{mg} / \mathrm{ml}$ ), which proves the efficiency of the synergetic effect of different phenolic compounds found in grape extracts.

In addition, KAM 33 had a growth inhibition towards E. coli but less than the others because he is poorer in Resveratrol which proved that the Resveratrol is one of the responsible of the inhibition effect on the E. coli. So the inhibition of $E$. coli by KAM 33 is due to a synergetic antimicrobial effect between Gallic acid, p-Coumaric acid and Quercetin. And a synergetic effect between Resveratrol and Cinamic acid explained the E. coli inhibition by ITCF 4 .

Within a comparison between the antimicrobial effect of grape extracts against $E$. coli and $S$. arizonae, we noticed that KAM 33 have more effect on S. arizonae than E. coli. Therefore, Resveratrol has probably more effect on $E$. coli than S. arizonae because while testing the phenolic standards resveratrol on the two bacterial strains, a more pronounced effect on E. coli was detectable. Furthermore, KAM 33 the poorer extract in Resveratrol presents a good inhibition against S. arizonae. But KAM 33 is rich in flavonoid content. So, flavonoids present a good inhibition on S. arizonae. This is also proved by the fact that ITCF4, the poorer extract in flavonoid content represent the lower inhibition of $S$. arizonae. This result showed the importance of the role of flavonoid component on the antimicrobial activity. Anastasiadi et al. (2009) [52] showed that flavonoids are known to possess antibacterial activities, which have been attributed to their interaction with extracellular soluble proteins and/or bacterial cell walls.

Antimicrobial activity of Chloramphenicol, phenolic standards and red grape extracts toward L. monocytogenes (Gram-positive strain) and C. albicans (yeast strain) are presented respectively in Figures $\mathbf{4}$ and $\mathbf{5}$.

Figure 5 showed that Amphotericin B presented the highest growth inhibition on C. albicans, and that a natural phenolic compound has more effect than synthetic phenolic compounds (BHT).

Furthermore, Figures $\mathbf{4}$ and $\mathbf{5}$ showed that ITS9 and ITCF4 exhibit the same inhibition profile against $L$. monocytogenes and C. albicans. ITCF4 and ITS9 are not the richer compound in flavonoid content but are the richer in phenolic acid, mainly in Cinnamic acid, known by its inhibition activity against $L$. monocytogenes [53] and C. albicans. Phenolic acids are the most active com- ponents in inhibiting the growth of pathogens. In fact, TACS22 does not contain Cinnamic acid but contains Hydroxybenzoic acid which has a near structure. But, Cinnamic acids, due to their propenoic side chain, are much less polar than the corresponding Hydroxybenzoic acids and this property might facilitate the transport of these molecules across the cell membrane, which might be related in turn to the stronger inhibitory effect [54]. For KAM 33, it is mainly p-Coumaric acid and Gallic acid which are responsible of the inhibition activity. This result is in agreement with several studies. Masquelier, 1988 [55] showed that p-Coumaric acid is particularly active against Gram-positive bacteria. Rodriguez Vaquero, 2007 [56] showed also that flavonoid are active

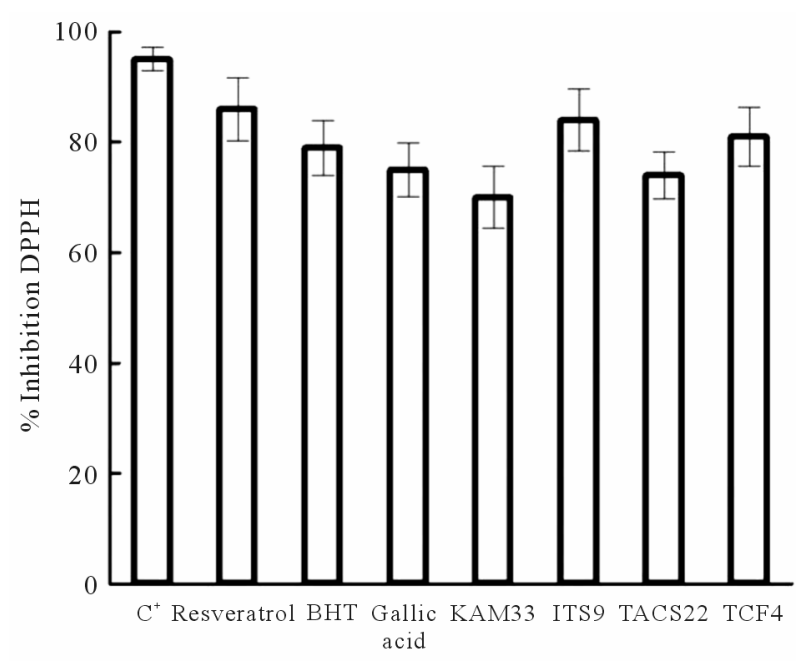

Figure 4. Antimicrobial activity of $\mathrm{C}^{+}$, phenolic standards and red grape extracts of vintage 2009 against Gram-positive strain.

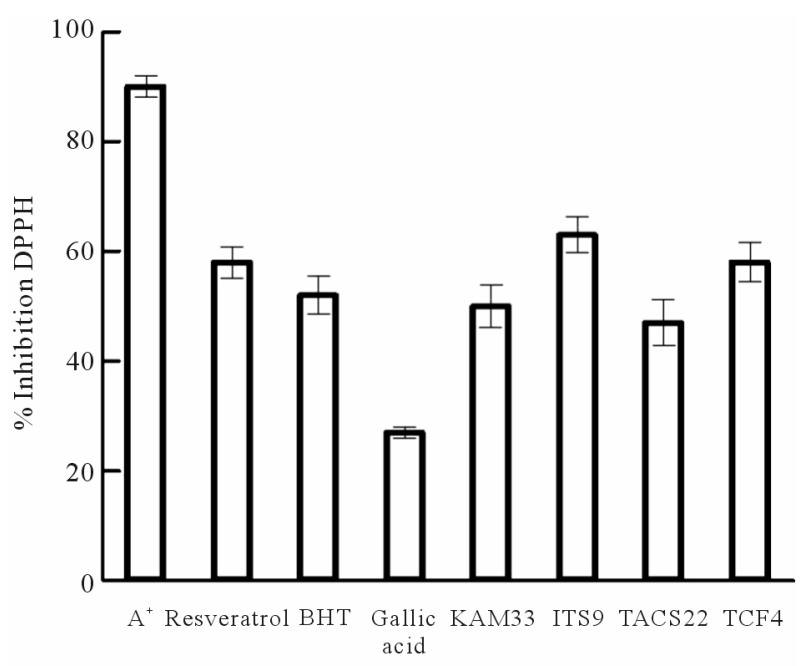

Figure 5. Antimicrobial activity of Amphotericin $B\left(A^{+}\right)$, phenolic standards and red grape extracts of vintage 2009 against a fungi strain. 
Table 7. Antimicrobial activity of the extracts.

\begin{tabular}{|c|c|c|c|c|c|}
\hline \multirow{2}{*}{ Grape varieties } & \multirow{2}{*}{ Codex } & \multicolumn{2}{|c|}{$\%$ growth inhibition Gram-negative } & \multirow{2}{*}{$\begin{array}{c}\begin{array}{c}\% \text { growth inhibition } \\
\text { Gram-positive }\end{array} \\
\text { Listeria monocytogenes }\end{array}$} & \multirow{2}{*}{$\begin{array}{c}\% \text { growth inhibition } \\
\text { Fungi } \\
\text { Candida albicans }\end{array}$} \\
\hline & & E. coli & Salmonella arizonae & & \\
\hline Merlot & KAM33 & $53^{\mathrm{d}}$ & $63^{\mathrm{d}}$ & $70^{\mathrm{d}}$ & $50^{\mathrm{c}}$ \\
\hline Syrah & ITS9 & $78^{\mathrm{a}}$ & $76^{\mathrm{a}}$ & $84^{\mathrm{a}}$ & $63^{\mathrm{a}}$ \\
\hline Cabernet Sauvignon & TACS22 & $68^{\mathrm{b}}$ & $69^{\mathrm{b}}$ & $74^{\mathrm{c}}$ & $47^{\mathrm{d}}$ \\
\hline Cabernet Franc & ITCF4 & $63^{\mathrm{c}}$ & $65^{\mathrm{c}}$ & $81^{\mathrm{b}}$ & $58^{\mathrm{b}}$ \\
\hline
\end{tabular}

$\overline{\mathrm{a}, \mathrm{b}, \mathrm{c}, \mathrm{d}}$ Marks with the same superscript letters were not significantly different within the same column (LSD test, $5 \%$ level).

against $L$. monocytogenes. These results showed that this observation may be rationalized considering the possible synergistic activity among polyphenols that is applied in the extracts.

The antimicrobial activity pattern of red grape extracts indicates that different classes of phenolic compounds are most likely to be the active substances in inhibiting the growth of E.coli, S. arizonae, L. monocytogenes and C. albicans. The summary of the antimicrobial activities of the red grape extracts against theses bacterial and fungal strains is presented in Table 7. The values shown are the means from duplicate experimental performed twice on every strain. Significant differences were observed between antimicrobial activities of the different grapes cultivars.

Table 7 showed that most of the grape extracts exhibited some kind of antimicrobial activity against bacterial and fungal strains. But this response varies, depending on the tested microorganism to grape extracts. The L. monocytogenes was the most sensitive microorganism. In almost all grape extracts, the inhibition for Listeria monocytogenes (Gram-positive) was greater than for E. coli and S. arizonae (Gram-negative strains), indicating that the Gram-positive strain was more sensitive than the Gram-negative ones. Our results were in agreement with several studies done on the antimicrobial activity of wine extracts on Gram-positive strain and Gram-negative strains. Jayaprakaska et al. 2003, and Papadopoulou et al., 2005, [14,28]. showed that phenolic extracts were more effective antibacterial fraction against Gram-positive bacteria when compared to Gram-negative bacteria. This observation can be attributed to differences in the structure of bacteria cell wall. The less complex structure of the cell wall in the Gram-positive bacteria makes it more permeable to the antimicrobial compounds.

Furthermore, Table 7 showed that the tested bacteria showed more sensitivity to the investigated extracts than the yeast strain. In all tests, the inhibition of C. albicans was smaller than the inhibition measured for L. monocytogenes, E. coli and S. arizonae. It appears that the yeast strains were more resistant to wine phenolics than the bacterial strains, which has been observed by other researchers too $[14,28,50]$. These different resistant patterns are likely to be related to differences in yeast and bacterial cell wall structures and in protein synthesis.

\section{Conclusion}

In the present work, we report the investigation on scavenging and antimicrobial activities of Lebanese grape extracts, to exploit their potential as natural preservatives. According to the results of the present screening study, we can emphasize on the great variability in the composition of phenolic compounds between red grape cultivars. It is well known that phenolic composition of grapes depends on multiple factors including climate, degree of ripeness, berry size and grapevine variety. Our study demonstrates that grape extracts present important scavenging and antimicrobial activities, corroborating the relevance of grape as a healthy alimentary product and a source of antioxidant and multiresistant bacteria drug substances. A synergistic effect of various phenolic compounds contained in the extracts could explain the different physiological activities observed during this work. Our results if well exploited could lead to the production of high added value of clean natural products. These could be made available to the food, pharmaceutical and cosmetics industries.

\section{Acknowledgements}

The project was funded by the Research Council of Saint Joseph University-Lebanon (Project FS27).

\section{REFERENCES}

[1] L. D. Mello, M. D. P. T. Sotomayor and L. T. Kubota, "HRP-Based Amperometric Biosensor for the Polyphenols Determination in Vegetables Extract," Sensors and Actuators B, Vol. 96, No. 3, 2003, pp. 636-645. doi:10.1016/j.snb.2003.07.008

[2] R. S. Jackson, "Wine Sciences," Academic Press, New York, 1994 
[3] M. Pinelo, A. Arnous and A. S. Meyer, "Upgrading of Grape Skins: Significance of Plant Cell-Wall Structural Components and Extraction Techniques for Phenol Release," Trends in Food Science and Technology, Vol. 17, No. 11, 2006, pp. 579-590. doi:10.1016/i.tifs.2006.05.003

[4] N. Balasundram, K. Sundram and S. Samman, "Phenolic Compounds in Plant and Agri-Industrial Byproducts: Antioxidant Activity, Occurrence, and Potential Uses," Food Chemistry, Vol. 99, No. 1, 2006, pp. 191-203. doi:10.1016/j.foodchem.2005.07.042

[5] M. D'Archivio, C. Filesi, R. Di Benedetto, R. Gargiulo, C. Giovannini and R. Masella, "Polyphenols, Dietary Sources and Bioavailability," Annali dell'Istituto Superiore di Sanità, Vol. 43, No. 4, 2007, pp. 348-361.

[6] S. Gómez-Alonso, E. García-Romero and I. HermosínGutiérrez, "HPLC Analysis of Diverse Grape and Wine Phenolics Using Direct Injection and Multidetection by DAD and Fluorescence," Journal of Food Composition and Analysis, Vol. 20, No. 7, 2007, pp. 618-626. doi:10.1016/j.jfca.2007.03.002

[7] J. L. Robichaud and A. C. Noble, "Astringency and Bitterness of Selected Phenolics in Wine," Journal of the Science of Food and Agriculture, Vol. 53, No. 3, 1990, pp. 343-353. doi:10.1002/jsfa.2740530307

[8] P. Ribereau-Gayon, "Accident Ferroviaire en Dordogne Port-Sainte-Foy, 8 Septembre 1997," Médecine de Catastrophe-Urgences Collectives, Vol. 1, No. 1, 1998, 23 pages. doi:10.1016/S1279-8479(98)80010-4

[9] Y. Rolland, "Antioxydants Naturels Végétaux," OCL, Vol. 11, No. 6, 2004, pp. 419-424.

[10] I. Gülçin, Z. Huyut, M. Elmastaş and H. Y. Aboul-Enein, "Radical Scavenging and Antioxidant Activity of Tannic Acid," Arabian Journal of Chemistry, Vol. 3, No. 1, 2010, pp. 43-53. doi:10.1016/j.arabjc.2009.12.008

[11] R. Carpenter, M. N. O’Grady, Y. C. O’Callaghan, N. M. O'Brien and J. P. Kerry, "Evaluation of the Antioxidant Potential of Grape Seed and Bearberry Extracts in Raw and Cooked Pork," Meat Science, Vol. 76, No. 4, 2007, pp. 604-610. doi:10.1016/i.meatsci.2007.01.021

[12] A. T. Serra, A. Matias, V. M. Nunes, M. C. Leitão, D. Brito, R. Bronze, S. Silva, A. Pires, M. T. Crespo, M. V. San Romão and C. M. Duarte, "In Vitro Evaluation of Olive- and Grape-Based Natural Extracts as Potential Preservatives for Food," Innovative Food Science and Emerging Technologies, Vol. 9, No. 3, 2008, pp. 311-319. doi:10.1016/i.ifset.2007.07.011

[13] E.-Q. Xia, G.-F. Deng, Y.-J. Guo and H.-B. Li, "Biological Activities of Polyphenols from Grapes," International Journal of Molecular Sciences, Vol. 11, No. 2, 2010, pp. 622-646. doi:10.3390/ijms11020622

[14] C. Papadopoulou, K. Soulti and I. Roussis, "Antimicrobial Activity of Wine Phenolic Extracts," Food Technology and Biotechnology, Vol. 43, No. 1, 2005, pp. 41-46.

[15] A. Furiga, A. Lonvaud-Funel and C. Badet, "In Vitro Study of Antioxidant Capacity and Antibacterial Activity on Oral Anaerobes of a Grape Seed Extract," Food Chemistry, Vol. 13, No. 4, 2009, pp. 1037-1040.

\section{doi:10.1016/j.foodchem.2008.08.059}

[16] A. Ojeil, N. El Darra, Y. El Hajj, P. B. Mouncef, T. J. Rizk and R. G. Maroun, "Identification et Caracterisation de Composés Phénoliques Extraits Du Raisin Château KSARA," Lebanese Science Journal, Vol. 11, No. 2, 2010, pp. 117-131.

[17] P. Chrétien and J. Marsault, "Polyphenolic Potential of the Harvest, Impacts (Analytical and Organoleptic) of Harvest Dateson the Vinificationofred Wine Cabernet Francin Anjou," IFV Unité, d'Angers, 2003.

[18] S. Imbeault, S. Parent, J. F. Blais, M. Lagace and C. Uhland, "Use of Bacteriophages to Control the Populations of Aeromonas salmonicida Resistant to Antibiotic," Journal of Water Science, Vol. 19, 2006, pp. 275-282.

[19] Y. El Hajj, N. Louka, C. Nguyen and R. G. Maroun, "Low Cost Process for Phenolic Compounds Extraction from Cabernet Sauvignon Grapes (Vitis vinifera L. CV. Cabernet Sauvignon). Optimization by Response Surface Methodology," Food and Nutrition Sciences, Vol. 3, 2012, pp. 89-103. doi: $10.4236 /$ fns.2012.31014

[20] K. Slinkard and V. L. Singleton, "Total Phenol Analyses: Automation and Comparison with Manual Methods," American Journal of Enology and Viticulture, Vol. 28, No. 1, 1977, pp. 49-55.

[21] P. Ribereau-Gayon and E. Stonestreet, "Assays of Anthocyanins in Red Wine," Bulletin Société Chimiques Francaise, Vol. 9, No. 419, 1968, pp. 2649-2652.

[22] P. Ho, T. A. Hogg and M. C. M. Silva, "Application of a Liquid Chromatography for the Determination of Phenolic Compounds and Furans in Fortified Wines," Food Chemistry, Vol. 64, No. 1, 1999, pp. 115-122. doi:10.1016/S0308-8146(98)00115-0

[23] J. P. Rauha, S. Remes, M. Heinonem, A. Hopia, M. Kahkonen, T. Kujala, K. Pihhlaja, H. Vuorela and P. Vuorela, "Antimicrobial Effects of Finnish Plant Extracts Containing Flavonoids and Other Phenolic Compounds," Internationnal Journal of Food Microbiology, Vol. 56, No. 1, 2000, pp. 3-12.

[24] J. A. Pereira, A. P. G. Pereira, I. C. F. R. Ferreira, P. Valentao, P. B. Andrade, R. Seabra, L. Estevinho and A. Bento, "Table Olives from Portugal: Compounds Antioxidant Potential, and Antimicrobial Activity," Journal Agricultural and Food Chemistry, Vol. 54, No. 22, 2006, pp. 8425-9431. doi:10.1021/jf061769j

[25] A. T. Borchers, C. L. Keen and M. E. Gerstiwin, "Mushrooms, Tumors and Immunity: An Update," Experimental Biology and Medicine, Vol. 229, No. 5, 2004, pp. 393-406.

[26] M. A. Gyamfi, M. Yonamine and Y. Aniya, "Free-Radical Scavenging Action of Medicinal Herbs from Ghana: Thonningia Sanguine on Experimentally Induced Liver Injuries," General Pharmacology: The Vascular System, Vol. 32, No. 6, 1999, pp. 661-667. doi:10.1016/S0306-3623(98)00238-9

[27] S. Kallithraka, A. A.-A., Mohdaly, D. P. Makris and P. Kefalas, "Determination of Major Anthocyanin Pigments in Hellenicnative Grape Varieties (Vitis vinifera sp.): Association with Antiradical Activity," Journal of Food Composition and Analysis, Vol. 18, No. 5, 2005, pp. 375- 
386. doi:10.1016/i.jfca.2004.02.010

[28] G. K. Jayaprakasha, T. Selvi and K. K. Sakariah, "Antibacterial and Antioxidant Activities of Grape (Vitis vinifera) Seed Extracts," Food Research International, Vol. 36, No. 2, 2003, pp. 117-122. doi:10.1016/S0963-9969(02)00116-3

[29] P. Iacopini, M. Baldi, P. Storchi and L. Sebastiani, "Catechin, Epicatechin, Quercetin, Rutin and Resveratrol in Red Grape: Content, in Vitro Antioxidant Activity and Interactions," Journal of Food Composition and Analysis, Vol. 21, No. 8, 2008, pp. 589-598. doi:10.1016/j.jfca.2008.03.011

[30] J. M. Ryan and E. Revilla, "Anthocyanin Composition of Cabernet Sauvignon and Tempranillo Grapes at Different Stages of Ripening," Journal of Agricultural and Food Chemistry, Vol. 51, No. 11, 2003, pp. 3372-3378. doi:10.1021/jf020849u

[31] F. Pomar, M. Novo and A. Masa, "Varietal Differences among the Anthocyanin Profiles, of 50 Red Table Grape Cultivars Studied by High Performance Liquid Chromatography," Journal of Chromatography A, Vol. 1094, No. 1-2, 2005, pp. 34-41. doi:10.1016/j.chroma.2005.07.096

[32] P. Gatto, U. Vrhovsek, J. Muth, C. Segala, C. Romualdi and P. Fontana, "Ripening and Genotype Control Stilbene Accumulation in Healthy Grapes," Journal of Agricultural and Food Chemistry, Vol. 56, No. 24, 2008, pp. 1177311785. doi: $10.1021 /$ if 8017707

[33] N. Vivas, N. St-Cricq de Gaulejac, T. Demptos and Y. Glories, "The Phenolicripening of Red Grapes and the Relationship with the Quality of Wine, Comparison of the Cultivars," Merlot and Tempranillo, Bordeaux II, 1998 .

[34] S. R. Segade, E. S. Vázquez and E. D. Losada, "Influence of Ripeness Grade on Accumulation and Extractability of Grape Skin Anthocyanins in Different Cultivars," Journal of Food Composition and Analysis, Vol. 21, No. 8, 2008, pp. 599-607. doi:10.1016/j.jfca.2008.04.006

[35] M. Gil and J. Yuste, "Phenolic Maturity of Tempranillo Grapevine Trained as Goblet, under Different Soil and Climate Conditions in the Dueri Valley Area," Journal International des Sciences de la Vigne et du Vin, Vol. 38, No. 1, 2004, pp. 81-88.

[36] T. Sun and C. T. Ho, "Antioxidant Activities of Buckwheat Extracts," Food Chemistry, Vol. 90, No. 4, 2005, pp. 743-749. doi:10.1016/j.foodchem.2004.04.035

[37] Y. Yilmzaz and R. T. Toledo, "Major Flavonoids in Grape Seeds and Skins: Antioxidant Capacity of Catechin, Epicatechin and Gallic Acid," Journal of Agricultural and Food Chemistry, Vol. 52, No. 2, 2004, pp. 255-260. doi:10.1021/if030117h

[38] R. R. Montealegre, R. R. Peces, J. L. C. Vozmediano, J. M. Gascuena and E. G. Romero, "Phenolic Compounds in Skin and Seeds of Ten Grape Vitis vinifera Varieties Grown in a Warm Climate," Journal of Food Composition and Analysis, Vol. 19, No. 6-7, 2006, pp. 687-693. doi:10.1016/i.jfca.2005.05.003

[39] Y. Cai, M. Sun and H. Corke, "Antioxidant Activity of Betalains from Plants of the Amaranthaceae," Journal of Agricultural and Food Chemistry, Vol. 51, No. 8, 2003, pp. 2288-2294. doi:10.1021/jf030045u

[40] T. Saïdani, M. Ouerghemmi, I. A. Wannes, W. Ksouri, R. Zemni, H. Marzouk, B. Elyes and M. Kchouk, "Valorization of Three Varieties of Grape," Industrial Crops and Products, Vol. 30, No. 2, 2009, pp. 292-296. doi:10.1016/j.indcrop.2009.05.007

[41] M. Sadeghipour, R. Terreux and J. Phipps, "Flavonoids and Tyrosine Nitration: Structure-Activity Relationship Correlation with Enthalpy of Formation," Toxicology in Vitro, Vol. 19, No. 2, 2005, pp. 155-165. doi:10.1016/j.tiv.2004.06.009

[42] A. Ghiselli, M. Nardini, A. Baldi and C. Scaccini, "Antioxidant Activity of Different Phenolic Fractions Separated from an Italian Red Wine," Journal of Agricultural and Food Chemistry, Vol. 46, No. 2, 1998, pp. 361-367. doi:10.1021/jf970486b

[43] M. Ebrahimzadeh, S. M. Nabavi, S. F. Nabavi, F. Bahramian and A. Bekhradnia, "Antioxidant and Free Radical Scavenging Activity of $H$. officinalis, L. var.augustufolius, $V$. odorata, B. hyrcana and C. speciosum. Pakistan Journal of Pharmaceutical Sciences, Vol. 23, No. 1, 2010, pp. 29-34.

[44] N. Uri, "Mechanism of Antioxidation," In: W. O. Lundberg, Ed., Autoxidation and Antioxidants, Intersciences, New York, 1961

[45] D. E. Pratt and B. J. F. Hudson, "Natural Antioxidants Not Exploited Commercially in Food Antioxidants," In: B. J. F. Hudson, Ed., Elsevier Applied Science, London, 1990, pp. 171-191.

[46] G. Ruberto, A. Renda, C. Daquino, V. Amico, C. Spatafora, C. Tringali and N. D. Tommasi, "Polyphenol Constituents and Antioxidant Activity of Grape Pomace Extracts from Five Sicilian Red Grape Cultivars," Food Chemistry, Vol. 100, No. 1, 2007, pp. 203-210. doi:10.1016/j.foodchem.2005.09.041

[47] C. A. Rice-Evans, N. J. Miller and G. Paganga, "StructureAntioxidant Activity Relationship of Flavonoids and Phenolic Acids," Free Radicals in Biology and Medicine, Vol. 20, No. 7, 1996, pp. 933-956. doi:10.1016/0891-5849(95)02227-9

[48] D. Villano, M. S. Fernandez-Pachon, M. L. Moya, A. M. Troncoso and M. C. Garcia-Parrilla, "Radical Scavenging Ability of Polyphenolic Compounds towards DPPH Free Radical," Talanta, Vol. 71, No. 1, 2007, pp. 230-235. doi:10.1016/j.talanta.2006.03.050

[49] T. Maier, A. Schieber, D. R. Kammerer and R. Carle "Residues of Grape (Vitis vinifera L.) Seed Oil Production as a Valuable Source of Phenolic Antioxidants," Food Chemistry, Vol. 112, No. 3, 2009, pp. 551-559.

doi:10.1016/j.foodchem.2008.06.005

[50] L. Butkhup, S. Chowtivannakul, R. Gaensakoo, P. Prathepha and Samappito, "Study of the Phenolic Composition of Shiraz Red Grape Cultivar (Vitis vinifera L.) Cultivated in North-Eastern Thailand and Its Antioxidant and Antimicrobial Activity," South African Journal for Enology and Viticulture, Vol. 31, No. 2, 2010.

[51] G. Bisignano, A. Tomaino, R. Lo Cascio, G. Crisafi, N. Uccella and A. Saija, "On the in Vitro Antimicrobial Ac- 
tivity of Oeluropein and Hydroxytyrosol," Journal of Pharmacy and Pharmacology, Vol. 51, No. 8, 1999, pp. 971-974. doi:10.1211/0022357991773258

[52] M. Anastasiadi, N. G. Chorianopoulos, G. J. Nychas and S. A. Haroutounian, "Antilisteral Activities of PolyphenolRich Extracts of Grapes and Vinification Byproducts," Journal of Agriculture and Food Chemistry, Vol. 57, No. 2, 2004, pp. 457-463. doi:10.1021/jf8024979

[53] A. M. Wen, P. Delaquis, K. Stanich and P. Toivonen, "Antilisterial Activity of Selected Phenolic Acids," Food Microbiology, Vol. 20, No. 3, 2003, pp. 305-311. doi:10.1016/S0740-0020(02)00135-1

[54] F. M. Campos, J. A. Couto and T. A. Hogg, "Influence of
Phenolic Acids on Growth and Inactivation of Oenococcus oeni and Lactobacillus hilgardii," Journal of Applied Microbiology, Vol. 94, No. 2, 2003, pp. 167-173. doi:10.1046/j.1365-2672.2003.01801.x

[55] J. Masquelier, "Physiological Effects of Wine, Its Share in Alcoholism," Bulletin de l'Office International de la Vigne et du Vin, Vol. 61, 1988, pp. 555-577.

[56] M. J. Rodriguez-Vaquero, M. R. Alberto and M. C. Mancade-Nadra, "Influence of Phenolic Compounds from Wines on the Growth of Listeria monocytogenes," Food Control, Vol. 18, No. 5, 2007, pp. 587-593. doi:10.1016/j.foodcont.2006.02.005 